\title{
I.S.Mu.L.T. Reccomendations for Intra and Periarticular Injections during COVID-19 Pandemic
}

\author{
F. Oliva ${ }^{1}$, F. Vittadini' ${ }^{2}$ A. Frizziero ${ }^{3}$, C. Costantino ${ }^{3}$, A. Fusco 4 , A. Giai Via ${ }^{5}$, \\ C. Foti ${ }^{6}$, G. Nanni ${ }^{7}$, A. Forte ${ }^{8}$, C. Biz ${ }^{9}$, M.C. Vulpiani ${ }^{10}$, A. De Carli ${ }^{10}$, A.C. Berardi ${ }^{11}$, \\ M. Fini ${ }^{12}$, J. Padulo ${ }^{13}$, N. Maffulli ${ }^{1}$ \\ ${ }^{1}$ Department of Musculoskeletal Disorders, Faculty of Medicine and Surgery, University of Salerno, Salerno, Italy \\ ${ }^{2}$ Department of Physical and Rehabilitation Medicine, Casa di Cura Policlinico San Marco, Venice, Italy \\ ${ }^{3}$ Department of Medicine and Surgery, University of Parma, Parma, Italy \\ ${ }^{4}$ Clinical Laboratory of Experimental Neurorehabilitation, I.R.C.C.S. Santa Lucia Foundation, Rome, Italy \\ ${ }^{5}$ Department of Emergency and Acceptance, Orthopaedics and Traumatology Unit, San Camillo-Forlanini \\ Hospital, Rome, Italy \\ ${ }^{6}$ Physical and Rehabilitation Medicine, University of Rome Tor Vergata, Rome, Italy \\ ${ }^{7}$ Isokinetic Medical Group, FIFA Medical Centre of Excellence, Bologna, Italy \\ ${ }^{8}$ Biomedical Research Centre, Gruppo Forte, Salerno, Italy \\ ${ }^{9}$ Department of Surgery, Oncology and Gastroenterology DiSCOG, Orthopedic Clinic, University of Padova, \\ Padova, Italy \\ ${ }^{10}$ Physical Medicine and Rehabilitation Unit, Sant'Andrea Hospital, "Sapienza" University of Rome, Rome, Italy \\ ${ }^{11}$ UOC Immunohematology and Transfusion Medicine Laboratories, Laboratory of Stem Cells, Spirito Santo \\ Hospital, Pescara, Italy \\ ${ }^{12}$ Laboratory of Preclinical and Surgical Studies, Rizzoli Orthopedic Institute, Bologna, Italy \\ ${ }^{13}$ Department of Biomedical Sciences for Health, Università degli Studi di Milano, Milan, Italy
}

DOI:

10.32098/mltj.03.2020.00

\section{INTRODUCTION}

SARS-CoV-2 is the coronavirus involved for the ongoing pandemic, responsible of the disease that has been identified as COVID-19 (COronaVIrus Disease-19) (1,2).

In most cases, transmission occurs via saliva droplets in closed or poorly ventilated environments (particularly public and workplaces), unclean hands and rarely via contaminated surfaces (1).

At present, it is unclear whether SARS-CoV-2, can be harbored in the synovial fluid, though musculoskeletal symptoms as myalgia, arthralgia and asthenia are frequent (3-5). Rapid tests based on the identification of specific $\operatorname{IgM}$ and $\mathrm{IgG}$ antibodies should not replace the molecular test based on the identification of viral RNA from nasopharyngeal swabs $(6,7)$.

Serological testing can be used for research and retrospective epidemiological purposes, while the possible role in diagnosing ongoing SARS-CoV-2 infection need further evidence considering high false negative and false positive risk (5).

\section{PRE-TRIAGE AND OUTPATIENT ACCESS}

The first outpatient access should be preceded by a telephone triage 48-72 hours before the consultation, in which the operator should be supported by a dedicated question- 
naire (figure 1), aimed to unveil the possible presence of suspicious symptoms or close contacts. Triage should be repeated at each subsequent access, and patients should be instructed to alert the operators whether any change in health status occurred.

By telephone, the operator should also provide information on access rules:

1. The patient must wear a surgical mask.

2. The patient can be accompanied by only one person.

When suspicious symptoms are identified during telephone triage, the doctor should contact the patient directly, and invite them to contact the general practitioner (GP). GPs should also be alerted when patients meet the criteria of suspected or close contact of a confirmed case. For the purpose of the European Centre for Disease Prevention and Control, a close contact of a confirmed case, has been clearly defined (8).

When a patient attends the clinic should be measured the temperature with a contactless device.

When temperature is inferior to $37.5^{\circ} \mathrm{C}$, patients are allowed to access, providing them with all the necessary PPE. On the other hand, if the temperature exceeds $37.5^{\circ} \mathrm{C}$, the patient cannot access and will be referred to the GP.

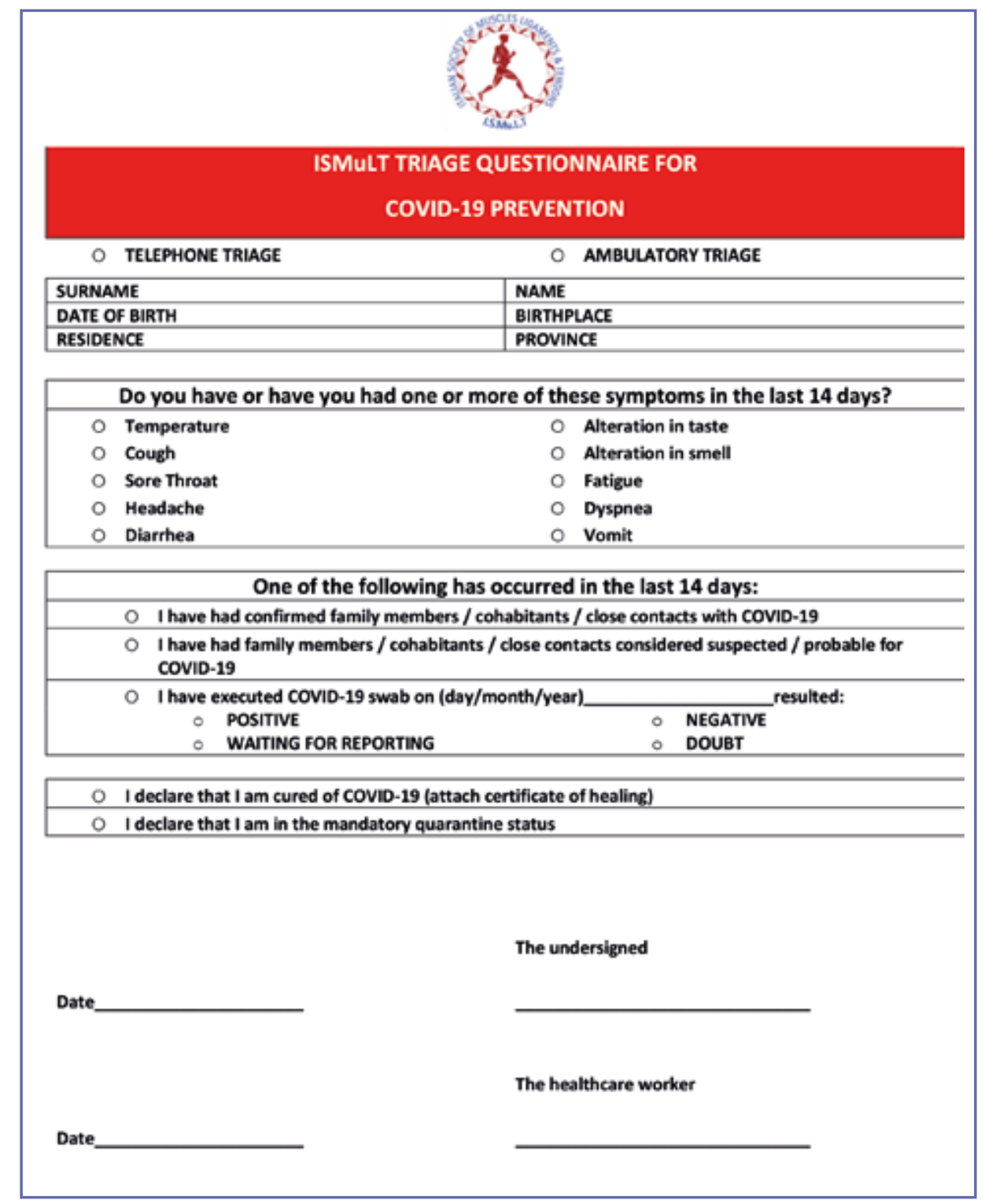

Figure 1. ISMuLT questionnaire. 


\section{AMBULATORY SETTING AND PREVENTIVE MEASURES}

Healthcare workers should always be equipped with PPE:

- since the injection procedure does not expose to droplets, the surgical mask should be sufficient (suspected or symptomatic cases cannot access to the procedure);

- the nurse equipped with a surgical mask may be present together with the doctor;

- the accompanying person should remain in the waiting room.

In ultrasound-guided and ultrasound-assisted procedures, the probe must be properly disinfected and a disposable probe cover should always be used (9).

It is mandatory to disinfect the contact surfaces (table, chairs) and the bench at each appointment.

Furthermore, appropriate ventilation of the environment must be ensured.

\section{INJECTION PROCEDURE}

Intra-articular and peri-articular injections can be practised in an ambulatory setting or in hospital outpatient department (10), according to a sequential procedure (table I).

Written or verbal informed consent should be obtained. In case of injection procedures, it is always necessary to discuss the risks, benefits and alternatives with the patient (12).

The presence of contraindications should be investigated:

- systemic infections;

- suspect or presence of infections at injection skin site or selected joint;

- fractures;

- prosthesis at injection site;

- coagulopathies;

- hypersensitivity to products.

Relative contraindications include:

- presence of infection in another site of the body;

- hypersensitivity to other injection products (not used);

- Diabetes Mellitus (10-12).

Injection therapy in patients on anticoagulant drugs or with known bleeding diathesis should be approached with great caution. All coagulation parameters should be evaluated in these patients, including prothrombin time (PT), activated partial thromboplastin time (aPTT), international normalized ratio (INR), and platelet count. Injections should be avoided with prolonged bleeding time, INR $>1.2$, and platelet count $<100,000 / \mu \mathrm{l}(12)$.

Various side effects can occur during the injection procedure; however, most adverse events are minor, transient and localized at the injection site (13).
Table I. Step-by-step procedure of intra-articular and periarticular injection (10-12).

\begin{tabular}{l} 
Clinical exam; evaluate injection indications; evaluate \\
comorbidities \\
\hline $\begin{array}{l}\text { Explain and sign the informed consent; discuss possible risks } \\
\text { and advantages }\end{array}$ \\
\hline $\begin{array}{l}\text { Preparation of the necessary instruments (disinfectant, sterile } \\
\text { material, drugs, needles, syringes, dressings); select needle } \\
\text { length and gauge }\end{array}$ \\
\hline Prepare patient; identify anatomical landmarks \\
\hline Skin disinfection; prepare sterile field \\
\hline Proceed with arthrocentesis when needed \\
\hline Proceed with injection \\
\hline Remove the needle rapidly after injection and perform local \\
compression with sterile gauze \\
\hline Disinfection and patch application \\
\hline $\begin{array}{l}\text { Instruct the patient to notice if any symptom or infection sign is } \\
\text { detected; schedule follow-up visit }\end{array}$ \\
\hline
\end{tabular}

The most common complications are sudden onset of local pain lasting no more than 72 hours $(2-10 \%$ of cases), skin atrophy $(1 \%)$, skin fat atrophy $(1 \%)$, and appearance of redness of the face (1-12\%) (13).

Less commonly reported side effects may include iatrogenic infection (risk of 1 in 1,000) and tendon rupture (less than $1 \%$ ). The risk of tendon rupture is higher during soft tissue injections around the Achilles tendon and plantar fascia (14).

Vasovagal episodes can occur with any type of injection procedure due to the nociceptive stimulation effect of the needle. The treatment is mainly supportive; it is rarely necessary to administer fluids and / or oxygen (12).

\section{Required equipment}

The equipment required is:

- gloves / sterile gloves;

- sterile swabs and sterile draps;

- prepacked sterile needles and syringes;

- disinfectant (iodopovidone / chlorexidhine);

- synovial fluid collection bottles;

- sterile ultrasound kit (only for US-guided injection);

- emergency kit $(10,15,16)$.

The choice of the right needle is mandatory, considering the characteristics of the target joint. A needle of 21 gauge should be preferred in large joints such as the shoulder or the knee, while 23-25 gouge needles are indicated in small joints. Deep joints such as the hip required spinal needles (length of 3,5 18 inches; 8-9 centimeters) $(10,12)$. 


\section{HYALURONIC ACID PROPERTIES}

Several studies support the role of viscosupplementation with hyaluronic acid (HA) in knee and hip osteoarthritis, in comparison to intra-articular corticosteroids (10,17-19). Emerging evidences suggest that the use of intra-articular corticosteroids could also determine a higher risk of viral infections, such as influenza, while no evidence about coronaviruses are currently found (20).

HA protects the articular environment through several mechanisms of action: anti-inflammatory effect, chondroprotection, analgesic effect, subchondral bone protection and increased production of endogenous HA (21).

\section{REFERENCES}

1. Contini C, Di Nuzzo M, Barp N, et al. The novel zoonotic COVID-19 pandemic: An expected global health concern. J Infect Dev Ctries 2020;14(3):254-264.

2. Ng OW, Tan YJ. Understanding bat SARS-like coronaviruses for the preparation of future coronavirus outbreaks - Implications for coronavirus vaccine development. Hum Vaccin Immunother 2017;13(1):186-189.

3. Cipollaro L, Giordano L, Padulo J, Oliva F, Maffulli N. Musculoskeletal symptoms in SARS-CoV-2 (COVID-19) patients. J Orthop Surg Res 2020;15(1):178. doi: 10.1186/ s13018-020-01702-w.

4. López-González MdC, Peral-Garrido ML, Calabuig I, et al. Case series of acute arthritis during COVID-19 admission. Ann Rheum Dis 2020 http://dx.doi.org/10.1136/annrheumdis-2020-217914.

5. Alivernini S, Cingolani A, Gessi M, et al. Comparative analysis of synovial inflammation after SARS-CoV-2 infection. Ann Rheum Dis 2020;annrheumdis-2020-218315. doi: 10.1136/ annrheumdis-2020-218315.

6. WHO. Laboratory testing for coronavirus disease (COVID19) in suspected human cases. Interim Guidance March 2020.

7. WHO. Laboratory testing strategy recommendations for COVID-19. Interim Guidance March 2020.

8. European Centrefor Disease Prevention and Control. www.ecdc. europa.eu/en/covid-19/surveillance/surveillance-definitions.
9. Nyhsen CM, Humphreys H, Nicolau C, Mostbeck G, Claudon M. Infection Prevention and Ultrasound Probe Decontamination Practices in Europe: A Survey of the European Society of Radiology. Insights Imaging 2016;7(6):841-847.

10. Frizziero A, Vittadini F, Oliva F, et al. I.S.Mu.L.T. Hyaluronic acid injections in musculoskeletal disorders guidelines MLTJ 2018;8(3)364-398. doi: 10.32098/mltj.03.2018.04.

11. Stephens MB, Beutler AI, O'Connor FG. Musculoskeletal injections: a review of the evidence. Am Fam Physician 2008;78(8):971-6.

12. Douglas L, PCRS Members. The Primary Care Rheumatology Society Joint and Soft Tissue Injection Guidelines. The Primary Care Rheumatology Society 2014;12 p.

13. Falco FJE, Obi Onyewu C, Lee Irwin F Jr, Kim DW, Zhu J. Peripheral Joint, Soft Tissue and Splnal Injection Techniques. In: Braddom RL (eds). Physical Medicine and Rehabilitation. 3rd edition. Elsevier Health Science, 2006:pp. 541-562.

14. Courtney P, Doherty M. Joint aspiration and injection. Best Pract Res Clin Rheumatol 2005;19(3):345-69.

15. Kaux JF, Samson A, Crielaard JM. Hyaluronic acid and tendon lesions. Mus Lig Ten J 2015;5(4):264-269. doi: 10.11138/mltj/2015.5.3.264.

16. Jackson DW, Evans NA, Thomas BM. Accuracy of needle placement into the intra-articular space of the knee. J Bone Joint Surg Am 2002;84-A(9):1522-7.

17. Piccirilli E, Oliva F, Aconstantinesei Murè M, et al. Viscosupplementation with intra-articular hyaluronic acid for hip disorders. A systematic review and meta-analysis. Mus Lig Ten J 2016;6(3):293-299. doi: 10.11138/mltj/2016.6.3.293.

18. Henrotin Y, Raman R, Richette P, et al. Consensus statement on viscosupplementation with hyaluronic acid for the management of osteoarthritis. Semin Arthritis Rheum 2015;45(2):140-9.

19. Ayhan E, Kesmezacar H, Akgun I. Intraarticular injections (corticosteroid, hyaluronic acid, platelet rich plasma) for the knee osteoarthritis. World J Orthop 2014;5(3):351-61.

20. Sytsma TT, Greenlund LK, Greenlund LS. Joint Corticosteroid Injection Associated With Increased Influenza Risk. Mayo Clin Proc Innov Qual Outcomes 2018;2(2):194-198.

21. Altman RD, Manjoo A, Fierlinger A, Niazi F, Nicholls M. The mechanism of action for hyaluronic acid treatment in the osteoarthritic knee: a systematic review. BMC Musculoskel Dis $2015 ; 16: 321$. 